\title{
Validation of rapid shallow breathing index displayed by the ventilator compared to the standard technique in patients with readiness for weaning
}

\author{
Nuttapol Rittayamai ${ }^{1 *}$, Natwipha Ratchaneewong $^{2,3}$, Pirat Tanomsina $^{1}$ and Withoon Kongla ${ }^{1}$
}

\begin{abstract}
Background: Rapid shallow breathing index (RSBI) is the most commonly used parameter for predicting weaning outcome. Measurement of RSBI by Wright spirometer (RSBI $\left.\right|_{\text {standard }}$ ) is the standard method in routine clinical practice. Data specific to the accuracy and reliability of the RSBI value displayed by the ventilator (RSBI vent $)$ are scarce. Accordingly, this study aimed to evaluate the association between the average value of RSBI vent $_{\text {t }}$ at different time points and $\mathrm{RSBI}_{\text {standard, }}$ and to assess the accuracy and reliability of these two RSBI measurement techniques.
\end{abstract}

Methods: This prospective cohort study included mechanically ventilated patients who were ready to wean. At the beginning of spontaneous breathing trial using the flow-by method, RSBI was measured by two different techniques at the same time, including: (1) Wright spirometer (breathing frequency/average tidal volume in $1 \mathrm{~min}$ ) ( $\left(\mathrm{RSBI}_{\text {standard }}\right.$ ), and (2) the values displayed on the ventilator at $0,15,30,45$, and $60 \mathrm{~s}$ (RSBI vent $)$.

Results: Forty-seven patients were enrolled. The RSBI ${ }_{\text {vent }}$ value was significantly higher than the $\mathrm{RSBI}_{\text {standard }}$ value for every comparison. According to Spearman's correlation coefficient ( $r$ ) and intraclass correlation coefficient (ICC), the average value of RSBI from 5 time points $(0,15,30,45$, and 60 s) showed the best correlation with the standard technique $(r=0.76[P<0.001]$, and ICC $=0.79$ [95\% Cl 0.61-0.88], respectively). Bland-Altman plot also showed the best agreement between $\mathrm{RSBl}_{\text {standard }}$ and the $\mathrm{RSBl} \mathrm{v}_{\text {vent }}$ value averaged among 5 time points (mean difference - 17.1 breaths/min/L).

Conclusions: We found that the ventilator significantly overestimates the RSBI value compared to the standard tech-

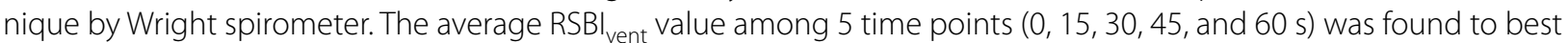
correlate with $\mathrm{RSBl}_{\text {standard }}$.

Keywords: Mechanically ventilated patients, Rapid shallow breathing index, Ventilator, Wright spirometer, Weaning

*Correspondence: nuttapol.rit@mahidol.ac.th

${ }^{1}$ Division of Respiratory Diseases and Tuberculosis, Department

of Medicine, Faculty of Medicine Siriraj Hospital, Mahidol University, 2

Wanglang Road, Bangkoknoi, Bangkok 10700, Thailand

Full list of author information is available at the end of the article

\section{Background}

Mechanical ventilation is a life-saving treatment in critically ill patients with acute respiratory failure; however, prolonged mechanical ventilation significantly increases healthcare utilization and cost, and is associated with poor outcomes [1, 2]. Many studies reported that delayed discontinuation of mechanical ventilation increased the risk of ventilator-induced lung injury, 
ventilator-associated pneumonia, diaphragm myotrauma, and other complications [3-6]. Moreover, patients with prolonged mechanical ventilation have increased intensive care unit (ICU) length of stay and hospital mortality $[7,8]$.

Liberation or weaning from mechanical ventilation is an important process that can account for $40-60 \%$ of the total duration of mechanical ventilation $[9,10]$, and determination of the appropriate time to initiate weaning can be a challenge. Assessment of readiness to wean is an important step before performing a spontaneous breathing trial (SBT), and patient readiness should be evaluated as soon as possible after the patient recovers from acute respiratory failure. Several parameters have been proposed for predicting the weaning outcome. Rapid shallow breathing index (RSBI), defined as the ratio of breathing frequency to average tidal volume in 1 min (breaths/ $\min / \mathrm{L}$ ), has been shown to be one of the most accurate predictors of weaning outcome [11]. A cut-off value greater than 105 breaths/min/L has been used to predict weaning trial failure [12]. RSBI measurement using a Wright spirometer is a gold standard method; however, it requires a special instrument that might not be available at the bedside.

Many modern ICU ventilators measure and display the RSBI value; however, the value displayed on the ventilator may vary breath by breath according to the algorithm used for calculating the RSBI. In addition, ventilator settings, such as pressure augmentation, positive-end expiratory pressure (PEEP), and a bias flow may also affect ventilator measurement of the RSBI. Data specific to the accuracy and reliability of the RSBI value displayed by the ventilator $\left(\mathrm{RSBI}_{\mathrm{vent}}\right)$ compared with standard measurement of RSBI using a Wright spirometer (RSBI standard $_{\text {are }}$ ) are limited. Accordingly, the aim of this study was to evaluate the correlation between the average value of $\mathrm{RSBI}_{\text {vent }}$ at different time points and RSBI standard $_{\text {, }}$ and to assess the accuracy and reliability of these two RSBI measurement techniques. We hypothesized that using the average value of $\mathrm{RSBI}_{\text {vent }}$ among different time points would increase the evaluated performance parameters compared to $\mathrm{RSBI}_{\text {standard }}$.

\section{Methods}

\section{Study design and population}

This prospective cohort study included mechanically ventilated patients who were admitted to the Division of Respiratory Diseases and Tuberculosis of the Department of Medicine, Faculty of Medicine Siriraj Hospital, Mahidol University, Bangkok, Thailand during June 1st, 2019 to December 15th, 2019. The study protocol was approved by the Siriraj Institutional Review Board (SIRB) (certificate of approval no. 275/2018), and was registered in the Thai Clinical Trial Registry (\#TCTR20180606001). Written informed consent was obtained from each subject or their relatives.

Patients meeting all of the following criteria were eligible for inclusion: (1) age from 18-90 years; (2) on mechanical ventilation $>24 \mathrm{~h}$; and, (3) readiness to wean with all of the following[13]: stable hemodynamics (heart rate $<140$ beats/min, systolic blood pressure within $90-160 \mathrm{mmHg}$, receiving no or low-dose vasopressor [equivalent to dopamine $<5 \mathrm{mcg} / \mathrm{kg} / \mathrm{min}$ ]), adequate oxygenation (oxygen saturation by pulse oximetry $\left[\mathrm{SpO}_{2}\right] \geq 92 \%$ or arterial partial pressure of oxygen $\left(\mathrm{PaO}_{2}\right) /$ inspired oxygen fraction $\left.\left(\mathrm{FiO}_{2}\right) \geq 200 \mathrm{mmHg}\right)$ with pressure support $\leq 12 \mathrm{cmH}_{2} \mathrm{O}, \quad \mathrm{FiO}_{2} \leq 0.5$, and PEEP $\leq 8 \quad \mathrm{cmH}_{2} \mathrm{O}$, and adequate mental status (Glasgow Coma Scale $\geq 13$ and not receiving sedative drugs). Patients with tracheostomy tube, pregnant women, and uncooperative patients were excluded.

\section{Study protocol}

All subjects were ventilated using a VELA ventilator (Vyaire Medical, Inc., Mettawa, IL, USA) with head-ofbed elevation of $30^{\circ}-45^{\circ}$ throughout the study. Ventilators and circuits were calibrated to prevent measurement bias. Subjects were stabilized and continuously monitored for blood pressure, heart rate, breathing frequency, and $\mathrm{SpO}_{2}$ during the study period. Endotracheal aspiration of secretion was performed before starting the study protocol.

RSBI was measured at the beginning of SBT with a flow-by technique using the following ventilator settings: pressure support of $0 \mathrm{cmH}_{2} \mathrm{O}$, PEEP of $0 \mathrm{cmH}_{2} \mathrm{O}, \mathrm{FiO}_{2}$ of 0.4 , flow trigger of $2 \mathrm{~L} / \mathrm{min}$, and bias flow of $10 \mathrm{~L} / \mathrm{min}$. The "Ferraris Haloscale" Wright spirometer (Ferraris Medical, Inc., Louisville, CO, USA) was attached between endotracheal tube and Y-piece. Respiratory variables measured by the ventilator (i.e. tidal volume, breathing frequency, minute ventilation, and RSBI) were selected to show on the ventilator screen (Fig. 1). After the patient began spontaneous breathing with a flow-by technique for one minute, the two RSBI measurement techniques including $\mathrm{RSBI}_{\text {standard }}$ and $\mathrm{RSBI}_{\text {vent }}$ were simultaneously measured for one minute by the same examiner (NAR). $\mathrm{RSBI}_{\text {standard }}$ was defined as the standard method using Wright spirometer. RSBI $_{\text {vent }}$ was defined as the RSBI value measured and displayed by the ventilator. RSBI measurement was terminated if the subject met at least one of the following criteria: $\mathrm{SpO}_{2}<92 \%$, breathing frequency $\geq 35$ breaths/minute, heart rate $\geq 140$ beats/min, malignant arrhythmia, or systolic blood pressure $<90$ or $>160 \mathrm{mmHg}$. After completing the study protocol, the ventilator was returned to its pre-test settings. 


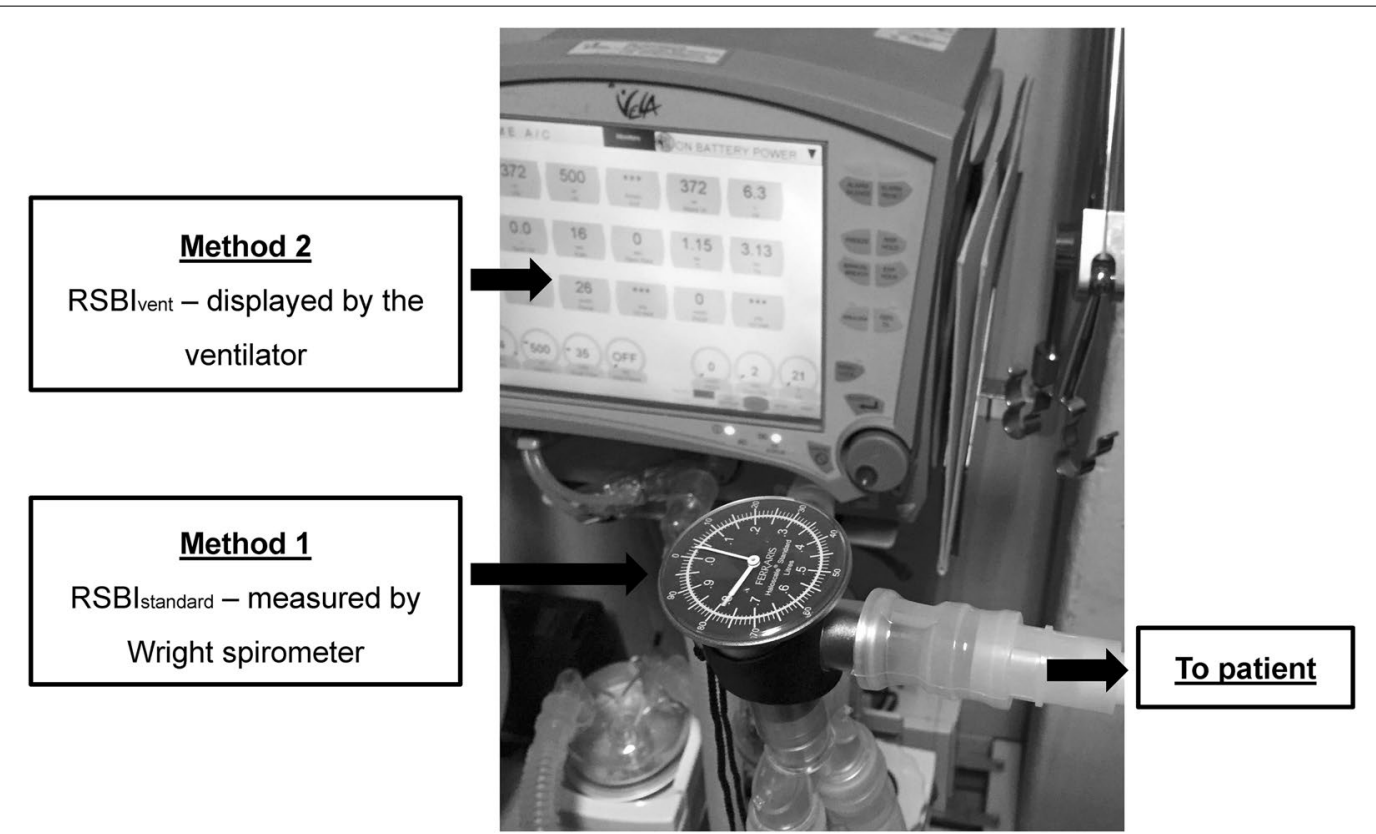

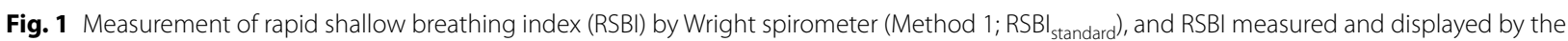
ventilator (Method 2; RSBI $\left.\right|_{\text {vent }}$ )

\section{Data collection}

Baseline characteristics that were recorded included age, gender, Acute Physiologic and Chronic Health Evaluation (APACHE) II score, comorbidity, type of respiratory failure, the principal diagnosis, and duration of mechanical ventilation. RSBI $_{\text {standard }}$ measured by Wright spirometer was calculated as the breathing frequency divided by average tidal volume (in liters) in $1 \mathrm{~min}$. The RSBI ${ }_{\text {vent }}$ value was recorded from the ventilator screen at $0,15,30$, 45 , and $60 \mathrm{~s}$ at the same time of measuring $\mathrm{RSBI}_{\text {standard }}$ using Wright spirometer in $1 \mathrm{~min}$. The average value of RSBI at different time points, including $0-15,0-30$, $0-45$, and $0-60 \mathrm{~s}$, was calculated.

\section{Outcomes}

The study outcomes were (1) the correlation between the average value of $\mathrm{RSBI}_{\mathrm{vent}}$ at different time points and $\mathrm{RSBI}_{\text {standard }}$, and (2) the accuracy and reliability of RSBI measurement by the two techniques.

\section{Statistical analysis}

Using data from a previous study [14], a 2 -sided $\alpha$ value of 0.05 , and a power of $80 \%$ a sample size of 47 patients was calculated to evaluate the accuracy and reliability between the two RSBI measurement techniques. Normality of data distribution was tested by Kolmogorov-Smirnov test. Continuous data are presented as mean \pm standard deviation or median [interquartile range] as appropriate. Categorical variables are presented as absolute number and percentage. We performed a correlation analysis between the two techniques using Spearman's correlation coefficient $(r)$ and intraclass correlation coefficient (ICC). Bland-Altman plot was used to evaluate the limit of agreement between $\mathrm{RSBI}_{\text {vent }}$ and

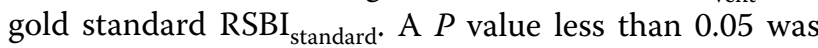
considered statistically significant. Statistical analysis was performed using PASW Statistics 18 (SPSS, Inc., Chicago, Illinois, USA) and MedCalc Statistical Software (Ostend, Belgium).

\section{Results}

Forty-seven mechanically ventilated subjects were enrolled. The median [interquartile range] age of subjects was 68.0 [60.0-75.0] years, $57.4 \%$ of them were female, and APACHE II score was 18.0 [17.0-20.0]. Pneumonia was the leading cause of hospital admission (44.7\%) followed by congestive heart failure (19.1\%) and extrapulmonary sepsis $(17.0 \%)$. Other baseline characteristics are presented in Table 1.

The median [interquartile range] $\mathrm{RSBI}_{\text {standard }}$ value was 66.0 [38.2-90.0] breaths $/ \mathrm{min} / \mathrm{L}$. The average RSBI ${ }_{\text {vent }}$ values at different time points are shown in Table 2. For all comparisons, the $\mathrm{RSBI}_{\text {vent }}$ value was significantly higher

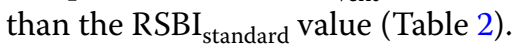


Table 1 Baseline demographics and clinical characteristics

\begin{tabular}{|c|c|}
\hline Variables & $N=47$ \\
\hline Age, years & $68.0[60.0-75.0]$ \\
\hline Female, n (\%) & $27(57.4 \%)$ \\
\hline Body mass index, $\mathrm{kg} / \mathrm{m}^{2}$ & 22.0 [20.8-24.0] \\
\hline \multicolumn{2}{|l|}{ Comorbidity, n (\%) } \\
\hline Hypertension & $31(66.0 \%)$ \\
\hline Diabetes mellitus & $19(40.4 \%)$ \\
\hline Cardiovascular disease & $10(21.3 \%)$ \\
\hline Respiratory disease & $7(14.9 \%)$ \\
\hline Chronic kidney disease & $9(19.1 \%)$ \\
\hline Chronic liver disease & $1(2.1 \%)$ \\
\hline Malignancy & $8(17.0 \%)$ \\
\hline Others & $6(12.8 \%)$ \\
\hline APACHE II at enrollment & $18.0[17.0-20.0]$ \\
\hline \multicolumn{2}{|c|}{ Principal diagnosis on admission, $\mathrm{n}(\%)$} \\
\hline Pneumonia & $21(44.7 \%)$ \\
\hline Congestive heart failure & $9(19.1 \%)$ \\
\hline Extrapulmonary sepsis & $8(17.0 \%)$ \\
\hline Acute exacerbation of COPD & $5(10.6 \%)$ \\
\hline Others & $4(8.3 \%)$ \\
\hline \multicolumn{2}{|c|}{ Type of acute respiratory failure, $\mathrm{n}(\%)$} \\
\hline Hypoxemic & $34(72.4 \%)$ \\
\hline Hypercapnic & $5(10.6 \%)$ \\
\hline Sepsis & $8(17.0 \%)$ \\
\hline
\end{tabular}

Data are presented as median [interquartile range] or $\mathrm{n}(\%)$

APACHE II Acute Physiology and Chronic Health Evaluation II, COPD chronic obstructive pulmonary disease

\section{Correlation and limit of agreement between $\mathrm{RSBI}_{\text {standard }}$ and $\mathrm{RSBI}_{\text {vent }}$}

Correlation analysis using Spearman's correlation coefficient revealed a strong statistically significant correlation between the average value of $\mathrm{RSBI}_{\text {vent }}$ at different time points and the RSBI $I_{\text {standard }}$ value (Table 3). The average value of $\mathrm{RSBI}_{\text {vent }}$ from 0 to $60 \mathrm{~s}$ demonstrated the best correlation with $\mathrm{RSBI}_{\text {standard }}(r=0.76 ; p<0.001)$ (Fig. 2).

Intraclass correlation coefficient demonstrated moderate to strong significant agreement between the average value of RSBI $I_{\text {vent }}$ at different time points and $R S B I_{\text {standard }}$ (Table 3), and the average value of $\mathrm{RSBI}_{\text {vent }}$ from $0-60 \mathrm{~s}$ had highest agreement with $\mathrm{RSBI}_{\text {standard }}$ (ICC $=0.79,95 \%$ CI $0.61-0.88 ; p<0.001$ ).

The mean difference between $\mathrm{RSBI}_{\text {standard }}$ and the average value of $\mathrm{RSBI}_{\text {vent }}$ at different time points is shown in Table 4. The average value of RSBI ${ }_{\text {vent }}$ from $0-60 \mathrm{~s} \mathrm{dem}$ onstrated the best agreement with $\mathrm{RSBI}_{\text {standard }}$ (mean difference between $\mathrm{RSBI}_{\text {standard }}$ and $\mathrm{RSBI}_{\text {vent }}$ from 0 to $60 \mathrm{~s}=-17.1 \mathrm{breaths} / \mathrm{min} / \mathrm{L}$, with a lower limit of -76.6 breaths $/ \mathrm{min} / \mathrm{L}$, and an upper limit of 42.4 breaths $/ \mathrm{min} / \mathrm{L}$ ) (Fig. 3).

\section{Discussion}

The results of this study showed that the ventilator significantly overestimated the RSBI value compared to the standard technique of RSBI measurement by Wright spirometer. However, using the average value of $\mathrm{RSBI}_{\text {vent }}$ from multiple different time points improved the accuracy of the $\mathrm{RSBI}_{\text {vent }}$ measurement. The average $\mathrm{RSBI}_{\text {vent }}$ value among 5 RSBI values $(0,0-15,0-30,0-45$, and 0-60 s) measured during $0-60 \mathrm{~s}$ demonstrated the best correlation and agreement with RSBI ${ }_{\text {standard }}$.

Weaning from mechanical ventilation is an important process in critically ill patients after they recover from acute respiratory failure. Assessment of readiness to wean is the first step, and several parameters have been used to assess pulmonary function and to predict weaning outcome, such as breathing frequency, minute ventilation, maximum inspiratory pressure, and RSBI $[13,15]$. RSBI, which is the ratio of breathing frequency divided by average tidal volume in one minute, is the most commonly used parameter in routine clinical practice, and a cut-off value below 105 breaths/min/L can predict the likelihood of weaning success [12, 16, 17].

Measurement of RSBI by Wright spirometer is a gold standard technique; however, it requires a special instrument that might not be available at the bedside. In addition, disconnecting the patient from the ventilator for a few minutes is required, and this may be harmful due

Table 2 Rapid shallow breathing index value measured by Wright spirometer and the average rapid shallow breathing index value displayed by the ventilator at different time points

\begin{tabular}{|c|c|c|c|c|}
\hline $\mathrm{RSBI}_{\text {standard, }}$ breaths/min/L & $\begin{array}{l}\text { Median [interquartile } \\
\text { range] }\end{array}$ & $\begin{array}{l}\text { Average } \mathrm{RSBI}_{\text {vent }} \text { at different time points, } \\
\text { breaths } / \mathrm{min} / \mathrm{L}\end{array}$ & Median [interquartile range] & $P$ value \\
\hline & $66.0[38.2-90.0]$ & At $0-15$ & $85.5[58.5-118.5]$ & $<0.001$ \\
\hline & $66.0[38.2-90.0]$ & At $0-30$ & $81.7[61.0-114.7]$ & $<0.001$ \\
\hline & $66.0[38.2-90.0]$ & At $0-45$ & $79.5[55.3-112.3]$ & $<0.001$ \\
\hline & $66.0[38.2-90.0]$ & At $0-60$ & $79.2[57.4-113.0]$ & $<0.001$ \\
\hline
\end{tabular}

Data are presented as median [interquartile range]

$R S B I_{\text {standard }}$ rapid shallow breathing index measured by Wright spirometer, $R S B I_{\text {vent }}$ rapid shallow breathing index displayed by the ventilator 
Table 3 Spearman's Correlation coefficient and intraclass correlation coefficient between the rapid shallow breathing index measured by the Wright spirometer and the average rapid shallow breathing index value displayed by the ventilator at different time points

\begin{tabular}{lccccc}
\hline & $\boldsymbol{r}$ & $\boldsymbol{P}$ value & ICC & $\mathbf{9 5 \%} \mathrm{Cl}$ & $\boldsymbol{P}$ value \\
\hline $\begin{array}{l}\text { Average RSB| } \\
\text { different }\end{array}$ at & & & & & \\
$0-15 \mathrm{~s}$ & 0.70 & $<0.001$ & 0.73 & $0.52-0.85$ & $<0.001$ \\
$0-30 \mathrm{~s}$ & 0.72 & $<0.001$ & 0.74 & $0.53-0.85$ & $<0.001$ \\
$0-45 \mathrm{~s}$ & 0.74 & $<0.001$ & 0.73 & $0.52-0.85$ & $<0.001$ \\
$0-60 \mathrm{~s}$ & 0.76 & $<0.001$ & 0.79 & $0.61-0.88$ & $<0.001$ \\
\hline
\end{tabular}

Cl confidence interval, ICC intraclass correlation coefficient, $r$ Spearman's correlation coefficient, $R S B I_{\text {standard }}$ rapid shallow breathing index measured by the Wright spirometer, $R S B I_{\text {vent }}$ rapid shallow breathing index displayed by the ventilator

to loss of PEEP effect and risk of contamination of the breathing tube and circuit. Measurement of RSBI using the value displayed by the ventilator during unassisted breathing such as flow-by method may be used to avoid the limitations of measuring RSBI by Wright spirometer. Furthermore, recent weaning guideline recommends using low pressure augmentation instead of T-piece or continuous positive airway pressure mode during SBT [18] then continuing pressure delivery with low pressure augmentation SBT after evaluating RSBI using the ventilator display would be preferred because disconnecting the patient from the ventilator is unnecessary.

Many modern ICU ventilators can measure and display the RSBI value; however, the displayed value may vary breath by breath according to both the algorithm used to calculate the RSBI value and patient's breathing pattern. Other factors, such as pressure augmentation, PEEP, and a bias flow may also affect the measurement of RSBI. Several studies reported the RSBI value to be significantly lower when applying low level of pressure support and/ or PEEP compared to unassisted breathing [19-23]. A bias flow in the flow trigger system may also influence the measurement of RSBI. A study by Kheir, et al.[24] found the RSBI value measured by the ventilator in the flow trigger mode to be significantly lower than during unassisted breathing. This can be explained by the effect of a bias flow in the flow trigger system that provides a small amount of pressure support that decreases work of breathing [25].

Very few studies have evaluated the accuracy of RSBI measured by the ventilator compared to the standard technique using Wright spirometer under the same ventilator condition at the same time. Patel et al. [23] measured RSBI during a flow-by mode using two different techniques, including the values measured and displayed by the ventilator, and the value measured by Wright spirometer attached to the expiratory port of the ventilator, in 91 subjects. They found no significant difference in RSBI between the two techniques; however, the measurements were not performed simultaneously. Lessa et al. [26] evaluated agreement between RSBI displayed by the ventilator during low level pressure support and digital ventilometer when the patient was disconnected from the ventilator in 22 subjects after postcardiac surgery. They found the RSBI to be significantly different between the two methods, but high agreement for RSBI, breathing frequency, and minute ventilation were still observed. In contrast, a study by de Sousa et al. [27] compared RSBI calculated by the ventilator during pressure support and PEEP of $5 \mathrm{cmH}_{2} \mathrm{O}$ and traditional method by spirometer. They found a strong correlation and intraobserver variation coefficient between the two methods.

Despite our finding that the RSBI value measured and displayed by the ventilator was consistently significantly higher than the RSBI value measured by the standard technique by Wright spirometer, we also found that adding more values of RSBI at different time points improved the accuracy of RSBI displayed by the ventilator compared to the standard technique. The measurement of RSBI from the two techniques in our study was performed simultaneously with same ventilator settings by the same examiner. These factors should improve the reliability and accuracy of our results compared to previous studies that made non-simultaneous comparisons and used different ventilator settings. Using the RSBI value measured and displayed by the ventilator is more convenient than the standard technique because it does not require a special instrument, and it can be performed without disconnecting the patient from the ventilator; however, using only a single ventilator-generated RSBI value may lead to an insufficiently accurate prediction of weaning outcome. We found that using the average of 5 ventilator-generated RSBI values during $0-60 \mathrm{~s}(0$, $0-15,0-30,0-45$, and $0-60 \mathrm{~s}$ ) improves the correlation between $\mathrm{RSBI}_{\text {vent }}$ and gold standard RSBI ${ }_{\text {standard }}$. In addition, continuous monitoring (longer than $1 \mathrm{~min}$ ) of RSBI using the value displayed by the ventilator may be more appropriate than using Wright spirometer in patient who is at risk for SBT failure (i.e. RSBI value between 90 and 110 breaths $/ \mathrm{min} / \mathrm{L}$ ) because disconnecting the patient from the ventilator is needed.

\section{Strength and limitations}

The strength of this study is that this is the first study to compare these two RSBI measurement techniques simultaneously in patients deemed ready to wean from ventilatory support. However, our study has some mentionable limitations. First, this is a single center study. 

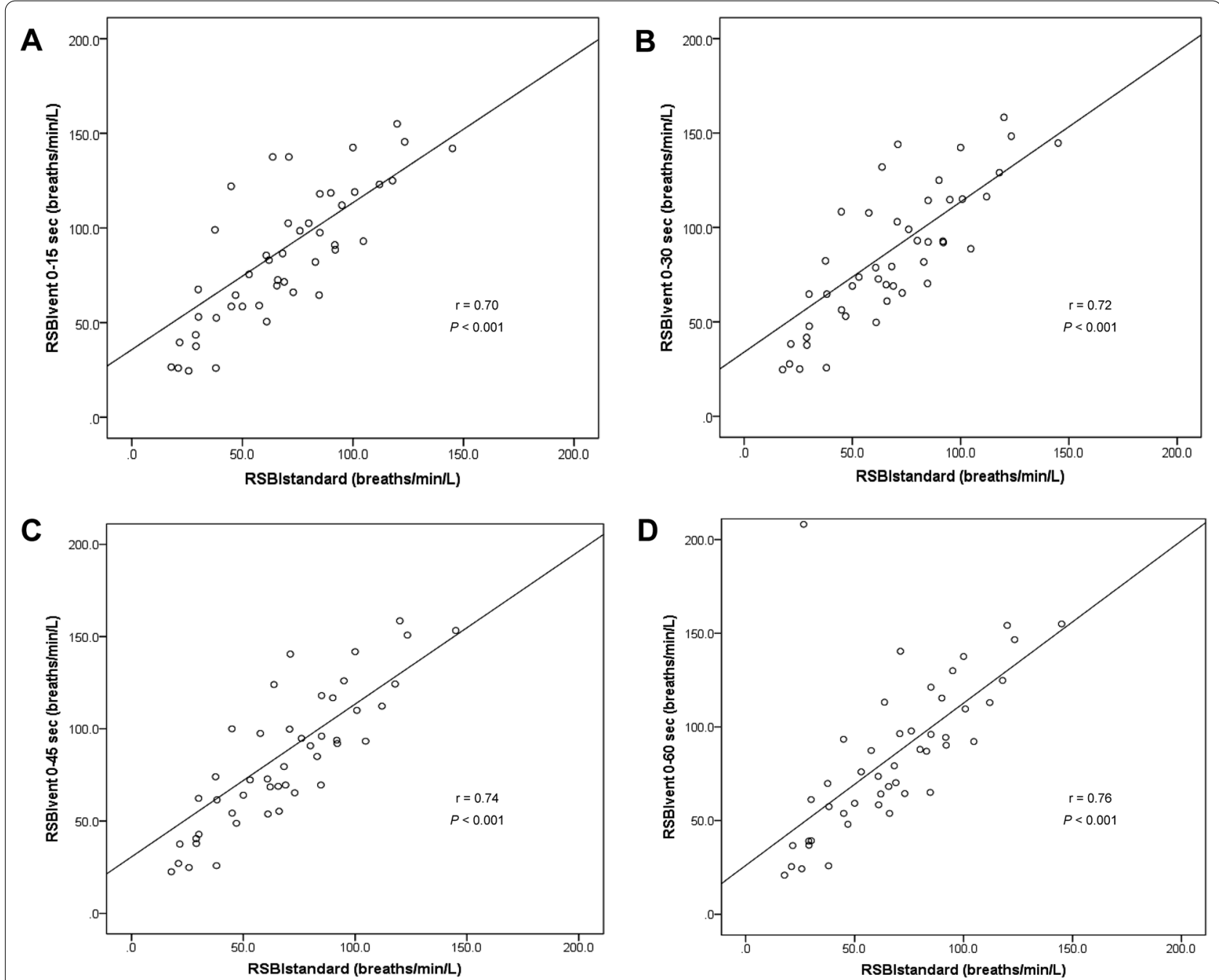

Fig. 2 Correlation between rapid shallow breathing index (RSBI) by Wright spirometer (RSBI standard) and the average RSBI value displayed by the ventilator $\left(\mathrm{RSBI}_{\text {vent }}\right)$ : a At 0-15 s, b At 0-30 s, c At 0-45 s, and d At 0-60 s

Second, only one brand of ventilator was used to evaluate the accuracy and reliability of $\mathrm{RSBI}_{\text {vent }}$ compared to the standard technique, so our findings may not be generalizable to other ventilator brands. Third, all measurements were done by the same examiner then the lack of interobserver comparison would limit the translatability into clinical practice. Last, we used a flow-by method during the measurement of RSBI. Using this method, the ventilator may deliver a small amount of pressure support, which means that the RSBI value might be lower than unassisted breathing.

\section{Conclusions}

The results of this study revealed that the ventilator significantly overestimates the RSBI value compared to the standard technique by Wright spirometer. The average $\mathrm{RSBI}_{\text {vent }}$
Table 4 Agreement of rapid shallow breathing index value measured by Wright spirometer and the average rapid shallow breathing index value displayed by the ventilator at different time points

\begin{tabular}{|c|c|c|c|}
\hline & Mean difference & Upper limit & Lower limit \\
\hline $\begin{array}{l}\mathrm{RSBI}_{\text {standard }}-\mathrm{RSBI}_{\text {vent }} \\
0-15 \mathrm{~s}\end{array}$ & -20.7 & 44.3 & -85.8 \\
\hline $\begin{array}{l}\left.R S B\right|_{\text {standard }}-\left.R S B\right|_{\text {vent }} \\
0-30 \mathrm{~s}\end{array}$ & -20.3 & 44.6 & -85.2 \\
\hline $\begin{array}{l}\left.R S B\right|_{\text {standard }}-\left.R S B\right|_{\text {vent }} \\
0-45 \mathrm{~s}\end{array}$ & -19.0 & 47.7 & -85.8 \\
\hline $\begin{array}{l}\mathrm{RSBI}_{\text {standard }}-\mathrm{RSBI}_{\text {vent }} \\
0-60 \mathrm{~s}\end{array}$ & -17.1 & 42.4 & -76.6 \\
\hline
\end{tabular}

$R S B I_{\text {standard }}$ rapid shallow breathing index measured by the Wright spirometer, $R S B I_{\text {vent }}$ rapid shallow breathing index displayed by the ventilator 

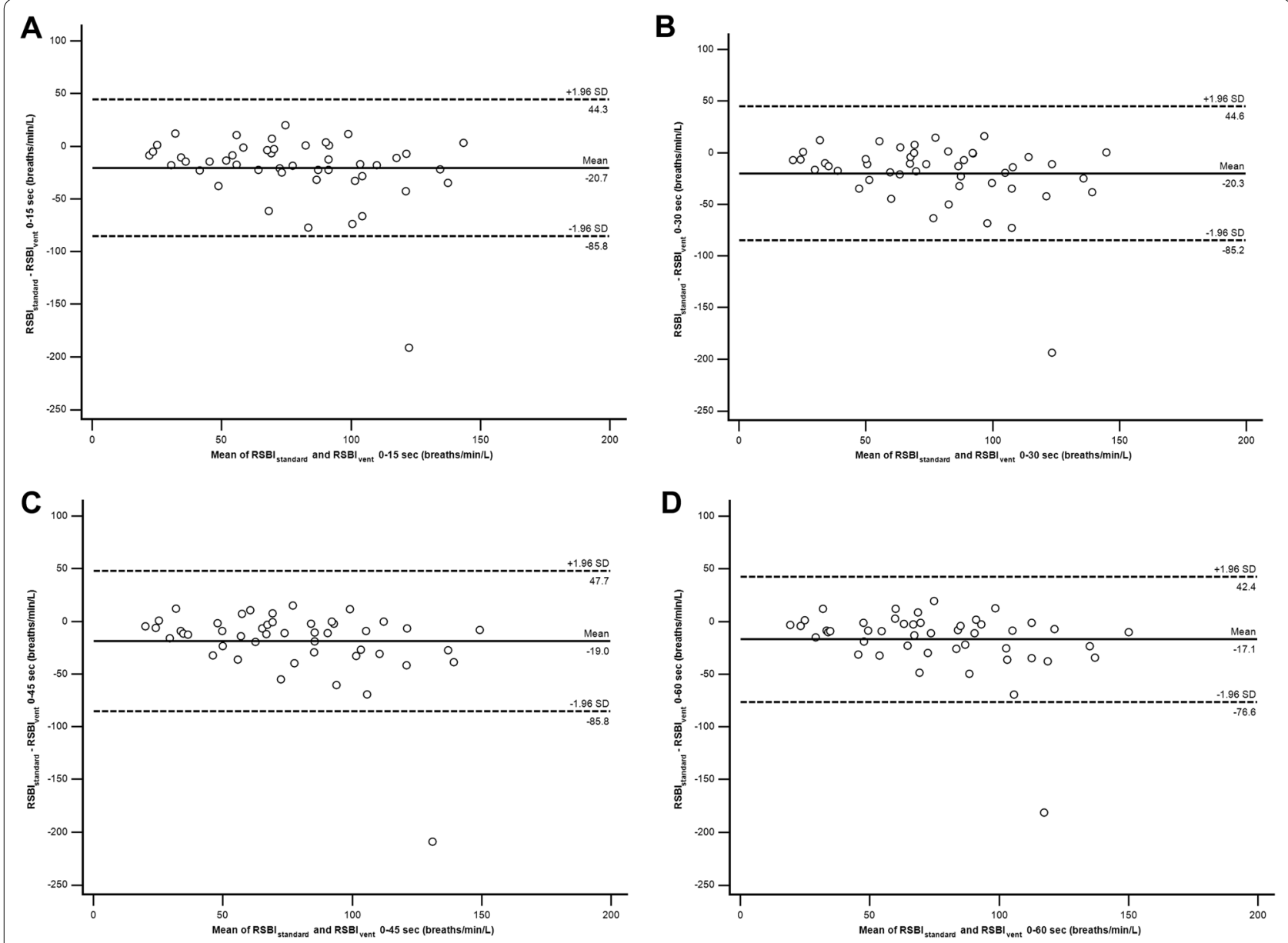

Fig. 3 Bland-Altman plot analysis of agreement between rapid shallow breathing index (RSBI) by Wright spirometer (RSBI standard) and the average value of RSBI displayed by the ventilator (RSBI vent $_{\text {t }}$ ): a At 0-15 s, b At 0-30 s, c At 0-45 s, and d At 0-60 s

value among 5 time points $(0,15,30,45$, and $60 \mathrm{~s})$ was found to have the best correlation with RSBI standard.

\section{Abbreviations}

APACHE: Acute Physiologic and Chronic Health Evaluation; Cl: Confidence interval; $\mathrm{FiO}_{2}$ : Inspired oxygen fraction; ICC: Intraclass correlation coefficient: ICU: Intensive care unit; $\mathrm{PaO}_{2}$ : Arterial partial pressure of oxygen; PEEP: Positive end-expiratory pressure; $r$ : Spearman's correlation coefficient; RSBI: Rapid shallow breathing index; $R S B I_{\text {standard: }}$ RSBI measured by Wright spirometer; $\mathrm{RSBI}_{\text {vent: }}$ $\mathrm{RSBI}$ displayed by the ventilator; $\mathrm{SBT}$ : Spontaneous breathing triali; $\mathrm{SpO}_{2}$ : Oxygen saturation by pulse oximetry.

\section{Acknowledgements}

The authors gratefully acknowledge Miss Khemajira Karaketklang (Department of Medicine, Faculty of Medicine Siriraj Hospital, Mahidol University) and Mr. Suthipol Udompunthurak (Research Group and Research Network Division, Research Department, Faculty of Medicine Siriraj Hospital, Mahidol University) for their assistance with statistical analysis.

\section{Authors' contributions}

NR and NAR conceived and designed the study. NR, NAR, PT, and WK collected the data. NR and NAR analyzed and interpreted the data. NR and NAR prepared the first draft of the manuscript. All authors critically reviewed and revised what would become the final version of the manuscript. All authors approved the final version of the manuscript, and are in agreement with the decision to submit this manuscript for journal publication.

\section{Funding}

This was an unfunded study.

\section{Availability of data and materials}

The datasets used and analyzed for this study are available from the corresponding author on reasonable request.

\section{Declarations}

\section{Ethics approval and consent to participate}

This study complied with the Declaration of Helsinki and was approved by the Siriraj Institutional Review Board (SIRB) (certificate of approval No. 275/2018). Written informed consent was obtained from all recruited subjects or their relatives.

\section{Competing interests}

The authors declare that they have no competing interest.

\section{Consent for publication}

Not applicable. 


\section{Author details}

${ }^{1}$ Division of Respiratory Diseases and Tuberculosis, Department of Medicine, Faculty of Medicine Siriraj Hospital, Mahidol University, 2 Wanglang Road, Bangkoknoi, Bangkok 10700, Thailand. ${ }^{2}$ Department of Medicine, Faculty of Medicine Siriraj Hospital, Mahidol University, Bangkok, Thailand. ${ }^{3}$ Department of Medicine, Chulabhorn Hospital, HRH Princess Chulabhorn College of Medical Science, Chulabhorn Royal Academy, Bangkok, Thailand.

Received: 7 July 2021 Accepted: 24 September 2021

Published online: 02 October 2021

\section{References}

1. Lone NI, Walsh TS. Prolonged mechanical ventilation in critically ill patients: epidemiology, outcomes and modelling the potential cost consequences of establishing a regional weaning unit. Crit Care. 2011;15(2):R102.

2. Hill AD, Fowler RA, Burns KEA, Rose L, Pinto RL, Scales DC. Long-term outcomes and health care utilization after prolonged mechanical ventilation. Ann Am Thorac Soc. 2017;14:355-62.

3. He Q, Wang W, Zhu S, Wang M, Kang Y, Zhang R, et al. The epidemiology and clinical outcomes of ventilator-associated events among 20,769 mechanically ventilated patients at intensive care units: an observational study. Crit Care. 2021;25(1):44.

4. Muscedere J, Sinuff T, Heyland DK, Dodek PM, Keenan SP, Wood G, et al. The clinical impact and preventability of ventilator-associated conditions in critically ill patients who are mechanically ventilated. Chest. 2013;144:1453-60.

5. Boyer AF, Schoenberg N, Babcock H, McMullen KM, Micek ST, Kollef MH. A prospective evaluation of ventilator-associated conditions and infectionrelated ventilator-associated conditions. Chest. 2015;147:68-81.

6. Goligher EC, Dres M, Fan E, Rubenfeld GD, Scales DC, Herridge MS, et al. Mechanical ventilation-induced diaphragm atrophy strongly impacts clinical outcomes. Am J Respir Crit Care Med. 2018;197:204-13.

7. Cox CE, Carson SS, Lindquist JH, Olsen MK, Govert JA, Chelluri L, et al. Differences in one-year health outcomes and resource utilization by definition of prolonged mechanical ventilation: a prospective cohort study. Crit Care. 2007;11(1):R9.

8. Béduneau G, Pham T, Schortgen F, Piquilloud L, Zogheib E, Jonas M, et al. Epidemiology of weaning outcome according to a new definition. The WIND Study. Am J Respir Crit Care Med. 2017;195:772-83.

9. Esteban A, Anzueto A, Frutos F, Alía I, Brochard L, Stewart TE, et al. Characteristics and outcomes in adult patients receiving mechanical ventilation: a 28-day international study. JAMA. 2002;287:345-55.

10. Esteban A, Ferguson ND, Meade MO, Frutos-Vivar F, Apezteguia C, Brochard $\mathrm{L}$, et al. Evolution of mechanical ventilation in response to clinical research. Am J Respir Crit Care Med. 2008;177:170-7.

11. Meade M, Guyatt G, Cook D, Griffith L, SinuffT, Kergl C, et al. Predicting success in weaning from mechanical ventilation. Chest. 2001;120(6 Suppl):400S-S424.

12. Yang KL, Tobin MJ. A prospective study of indexes predicting the outcome of trials of weaning from mechanical ventilation. N Engl J Med. 1991;324:1445-50.
13. Boles J-M, Bion J, Connors A, Herridge M, Marsh B, Melot C, et al. Weaning from mechanical ventilation. Eur Respir J. 2007;29:1033-56.

14. Demirtas Yilmaz S, Gürsel G, Aydogdu M. Determining the mechanical ventilation mode and pressure support combination that is best compatible with the rapid shallow breathing index calculated in spontaneous ventilation. Crit Care. 2014;18(Suppl 1):P267.

15. Sellarés J, Ferrer $M$, Torres $A$. Predictors of weaning after acute respiratory failure. Minerva Anestesiol. 2012;78:1046-53.

16. Yang KL. Reproducibility of weaning parameters A need for standardization. Chest. 1992;102:1829-32

17. El-Khatib MF, Bou-Khalil P. Clinical review: liberation from mechanical ventilation. Crit Care. 2008;12(4):221.

18. Schmidt GA, Girard TD, Kress JP, Morris PE, Ouellette DR, Alhazzani W, et al Official Executive Summary of an American Thoracic Society/American College of Chest Physicians Clinical Practice Guideline: Liberation from Mechanical Ventilation in Critically III Adults. Am J Respir Crit Care Med. 2017;195:115-9.

19. El-Khatib MF, Jamaleddine GW, Khoury AR, Obeid MY. Effect of continuous positive airway pressure on the rapid shallow breathing index in patients following cardiac surgery. Chest. 2002:121:475-9.

20. El-Khatib MF, Zeineldine SM, Jamaleddine GW. Effect of pressure support ventilation and positive end expiratory pressure on the rapid shallow breathing index in intensive care unit patients. Intensive Care Med. 2008;34:505-10.

21. Bien M-Y, Shui Lin Y, Shih C-H, Yang Y-L, Lin H-W, Bai K-J, et al. Comparisons of predictive performance of breathing pattern variability measured during T-piece, automatic tube compensation, and pressure support ventilation for weaning intensive care unit patients from mechanical ventilation. Crit Care Med. 2011:39:2253-62.

22. Desai NR, Myers L, Simeone F. Comparison of 3 different methods used to measure the rapid shallow breathing index. J Crit Care. 2012;27(418):e1-6.

23. Patel KN, Ganatra KD, Bates JHT, Young MP. Variation in the rapid shallow breathing index associated with common measurement techniques and conditions. Respir Care. 2009;54:1462-6.

24. Kheir F, Myers L, Desai NR, Simeone F. The effect of flow trigger on rapid shallow breathing index measured through the ventilator. J Intensive Care Med. 2015;30:103-6.

25. Takeuchi M, Williams P, Hess D, Kacmarek RM. Continuous positive airway pressure in new-generation mechanical ventilators: a lung model study. Anesthesiology. 2002;96:162-72.

26. Lessa FAM, Paes CD, Tonella RM, Araújo S. Comparison of the rapid shallow breathing index (RSBI) calculated under direct and indirect form on the postoperative period of cardiac surgery. Rev Bras Fisioter. 2010;14(6):503-9.

27. de Souza LC, Lugon JR. The rapid shallow breathing index as a predictor of successful mechanical ventilation weaning: clinical utility when calculated from ventilator data. J Bras Pneumol. 2015:41(6):530-5.

\section{Publisher's Note}

Springer Nature remains neutral with regard to jurisdictional claims in published maps and institutional affiliations.

Ready to submit your research? Choose BMC and benefit from

- fast, convenient online submission

- thorough peer review by experienced researchers in your field

- rapid publication on acceptance

- support for research data, including large and complex data types

- gold Open Access which fosters wider collaboration and increased citations

- maximum visibility for your research: over 100M website views per year

At BMC, research is always in progress.

Learn more biomedcentral.com/submissions 